\title{
A insustentável leveza do trabalho em saúde: excessos e invisibilidade no trabalho da enfermagem em oncologia
}

\author{
The unbearable lightness of health work: overdemand and invisibility \\ on nursing work in oncology
}

Maria Liana Gesteira Fonseca', Marilene de Castilho Sá2

\begin{abstract}
RESUMO Este artigo aborda a produção do cuidado, focalizando particularmente o trabalho da enfermagem. Trata-se de uma pesquisa teórica, apoiada na psicodinâmica do trabalho, utilizando-se, para ilustração, de fragmentos de material oriundo de pesquisa em uma enfermaria oncológica. Conclui-se que o trabalho em saúde possui uma dimensão intangível - caracterizada pela inteligência criadora e sensibilidade do trabalhador - que é definitiva para a qualidade do cuidado e não pode ser mensurado por indicadores formais. Exigindo simultaneamente intensidade e leveza, o trabalho em saúde necessita ser sustentado, o que aponta para a importância da gestão em sua função de sustentação material e psíquica do trabalho em saúde.
\end{abstract}

PALAVRAS-CHAVE Assistência à saúde; Cuidados de enfermagem; Assistência hospitalar; Gestão em saúde.

ABSTRACT This article discusses the production of care, focusing particularly on nursing work. This is a theoretical study, based upon work psychodynamics, using, for illustration, empiric material from a research in an oncology sickroom. We conclude that health work has an intangible dimension - characterized by the workers' creative intelligence and sensitivity - which is definitive for health care quality and can not be measured by formal indicators. Requiring both strength and lightness, health work needs to be sustained, pointing to the importance of management for providing material and psychic support for health work.

KEYWORDS Delivery of health care; Nursing care; Hospital care; Health management.

\footnotetext{
1 Instituto Nacional do Câncer (Inca) - Rio de Janeiro (RJ), Brasil. liana.fonseca@inca.gov.br 


\section{Introdução}

Este artigo aborda as especificidades do trabalho em saúde e seus desafios para a gestão do trabalho nesse âmbito. Considerando os aspectos relacionais e intersubjetivos que são centrais neste tipo de trabalho (SCHRAIBER, 1993; MERHY, 2002; CAMPOS, 2003; AYRES, 2004; SÁ, 2005, 2009) e que atravessam as organizações de saúde, abordou-se o trabalho em saúde e a produção do cuidado especialmente em sua dimensão de 'saber-fazer discreto' (MOLINER, 2012), assim como o conceito de 'contaminação do tempo fora do trabalho' (SANTOS, 2001), para ilustrar a complexa trama que pode estar presente no vínculo dos trabalhadores de saúde com seu ofício. Focalizou-se particularmente o trabalho da enfermagem.

Apresentam-se então aqui resultados de uma pesquisa teórica, apoiada sobretudo na psicodinâmica do trabalho (DEJOURS, 1982, 1993, 2004, 2008A, 2012A, 2012B), utilizando-se, em caráter ilustrativo, de fragmentos de material empírico oriundo de uma pesquisa de campo ocorrida entre setembro de 2012 e junho de 2013, compreendendo entrevistas com trabalhadores de enfermagem de uma enfermaria oncológica e observação participante (FONSECA, 2014). Para este artigo, recortou-se a temática do vínculo dos trabalhadores com seu trabalho e a chamada 'contaminação do tempo fora do trabalho'.

\section{O trabalho em saúde e suas dimensões intangíveis}

O trabalho em saúde guarda especificidades que tornam seu gerenciamento mais complexo não só por se tratar de um trabalho que se dá entre sujeitos, portanto apresentando um caráter relacional central, mas também, principalmente, por significar intervir sobre a vida, os corpos e as paixões de sujeitos que se colocam no momento desse encontro como pacientes e usuários do sistema de saúde (SÁ, 2005; SCRAIBER, 1993).
É necessário compreender os desafios ou exigências que esse trabalho, por sua própria especificidade, impõe aos trabalhadores, bem como os impasses colocados pelo atual contexto de grandes mudanças na saúde pública e no gerenciamento dos serviços de saúde, especialmente dos hospitais, absortos na lógica dos resultados, indicadores e números - estes cobrados por instâncias superiores aos próprios serviços de saúde e por vezes incorporados pela lógica gerencialista dos gestores. A necessidade de metas, números e indicadores é justificável e justificada, tendo em vista as necessidades dos usuários do Sistema Único de Saúde (SUS) e o imperativo de se garantir universalidade e equidade no acesso aos serviços de saúde, com qualidade e eficiência no uso dos recursos públicos. No entanto, no setor de saúde, especialmente em áreas mais específicas, como a oncologia, por exemplo, as demandas crescem exponencialmente e nem sempre as condições de trabalho e de recursos humanos são condizentes com tais cobranças. Além disso, é importante considerar - o que será visto no presente artigo - que o trabalho em saúde possui uma dimensão intangível que é muito maior e muito mais definitiva para a qualidade do cuidado produzido do que aquilo que do trabalho pode ser mensurado ou apreendido por indicadores formais.

Por isso, é preciso observar mais de perto e buscar compreender o trabalho real (DEJOURS, 2008A, 2012A) dos operadores do cuidado, interrogando sobre sua distância e possíveis contradições com relação às prescrições, metas, aos indicadores e à dinâmica organizacional. O que esse tipo de trabalho demanda de seus trabalhadores? O que é visível e o que é invisível no trabalho de saúde? Esse trabalho seria plenamente passível de captura e mensuração pelos métodos disponíveis de gestão que se tem hoje? Como se expressa o vínculo entre trabalhador e organização/trabalho? 
Que elementos condicionam tal vínculo e quais os efeitos deste para a qualidade do cuidado em saúde?

Para começar, é preciso que se tome o conceito de trabalho. Para tanto, será usada a concepção da psicodinâmica do trabalho, desenvolvida por Christophe Dejours, que, baseada na ergonomia da atividade e em autores como Guérin, Laville, Daniellou, Duraffourg, Kerguelen, distingue o trabalho prescrito do trabalho real, afirmando que há sempre uma diferença entre aquilo que é solicitado pela organização formal do trabalho e aquilo que de fato trabalhadores e trabalhadoras realizam em seu cotidiano, de acordo com os eventos, com as variabilidades e as diversas necessidades emergentes, que demandam que a lacuna entre trabalho prescrito e trabalho real seja preenchida (DEJOURS, 2004, 2008A, 2012A, 2012B).

Tal lacuna é preenchida por aquilo que os sujeitos que trabalham acrescentam de si às prescrições. Segundo Dejours:

O que ainda aparece para o clínico como a característica maior do 'trabalhar', é que, mesmo que o trabalho seja bem concebido, a organização do trabalho seja rigorosa, as instruções e os procedimentos sejam claros, é impossível atingir a qualidade se as prescrições forem respeitadas escrupulosamente $[\ldots]$. O caminho a ser percorrido entre o prescrito e o real deve ser, a cada momento, inventado ou descoberto pelo sujeito que trabalha. 'Assim, para o clínico, o trabalho se define como sendo aquilo que o sujeito deve acrescentar às prescrições para poder atingir os objetivos que lhe são designados'. (DEJOURS, 2004, P. 28) [grifo das autoras].

O hiato gerado entre a organização prescrita do trabalho e a organização real solicita - a todo momento - da parte daquele que opera o trabalho uma atividade de concepção (DEJOURS, 2004) e mesmo de interpretação do mundo à sua volta (SÁ, 2005). Sendo assim, o trabalho em saúde é também, como todo trabalho, um trabalho de criação, de concepção, de produção de saber e de uso de capacidades e saberes tácitos.

É justamente no hiato entre estes dois polos, o trabalho prescrito e o trabalho real hiato este geralmente invisível para os atuais métodos de gestão -, que se encontram boa parte das produções subjetivas daquele que trabalha: sua inteligência criadora, seu prazer e seu sofrimento.

No caso dos trabalhos em saúde, devido à sua natureza eminentemente relacional (MERHY, 2002; SÁ, 2005, 2009) e ao próprio objeto do trabalho, a vida, que é sempre dinâmica e prenhe de variabilidades - o trabalhador está sempre acrescentando de si às prescrições, sempre ajustando as regras gerais, aos casos particulares e sempre lidando com situações singulares (BRITO, 2011; MARSIGLIA, 2011). No caso de trabalhos em saúde, como o da enfermagem, por exemplo, cujo aprendizado e trabalho prescrito se concentram principalmente na execução de procedimentos técnicos, a diferença entre o prescrito e o real fica ainda maior, na medida em que é preciso, além de aplicar as técnicas, lidar com um outro, em situação de extrema fragilidade, que se coloca à sua frente na qualidade de paciente e que está trazendo situações únicas e geralmente viscerais, plenas das mais intensas emoções, ligadas à vida, à morte, às dificuldades sociais. No entanto, a dimensão relacional desse tipo de trabalho nem sempre ganha seu peso seja na formação, no planejamento ou nos métodos de avaliação do trabalho.

Dejours (2012A) usa a metáfora do iceberg para definir o trabalho: aquilo que está acima da água e, portanto, é visível é apenas uma pequena parte do trabalho, o trabalho prescrito; o que está abaixo e que consiste em sua parte mais volumosa e invisível, principalmente para os métodos de gestão e avaliação, é o trabalho real, com suas variabilidades, imprevistos e com tudo aquilo que o trabalhador acrescenta de si para transformar a prescrição em algo concreto, em trabalho real. 


\section{Os trabalhos de cuidado os desafios do reconhecimento}

Tomando os trabalhos de cuidado como aqueles em que esta invisibilidade fica ainda mais acentuada, na medida em que há algo que lhe é fundamental e que escapa à visibilidade - aquilo que Dejours (2012B) e Pascale Molinier chamaram de 'savoir-faire discreto', o saber fazer discreto -, tem-se um problema no que tange aos métodos de avaliação: aquilo que o trabalho tem de essencial é invisível, não mensurável e imprescritível. Como trabalho invisível, é imaterial e difícil de ser capturado por métodos de gestão e avaliação, ainda que adquira extrema importância para a qualidade do cuidado.

Molinier (2012) destaca cinco dimensões dos trabalhos de cuidado: como 'savoirfaire discreto', tal como afirmado acima; como gentleness, no sentido de se antecipar às necessidades do outro sem lhe retirar seu estatuto de dignidade, como "trabalho sujo", no sentido de um trabalho com "os humores do corpo e as patologias da alma" (MOLINIER, 2012, P. 34), com tudo aquilo que não se quer ter contato; como "trabalho inestimável" (MOLINIER, 2012, P. 36), no sentido de não ser passível de mensuração e, finalmente, como 'narrativa ética', no sentido de fazer aquilo que deve ser feito, não como bondade ou caridade, mas como imperativo ético. Tais dimensões não são passíveis de ser plenamente avaliadas, visto que dificilmente podem ser capturadas por mensurações, ao mesmo tempo, são essenciais ao cuidado.

Na pesquisa empreendida entre setembro de 2012 e junho de 2013 com uma equipe de enfermagem de uma enfermaria em um hospital de oncologia no Rio de Janeiro (FONSECA, 2014), dentre vários relatos de exercício do cuidado, destacou-se este, que condensa as dimensões enunciadas por Molinier, quando uma técnica de enfermagem conta como faz a higiene íntima dos pacientes, como limpa seus excrementos:
Porque eu sei que aquele paciente não é aquele, aquele... não são aqueles excrementos. Que tudo aquilo é uma coisa natural. Que está em mim. Então, eu sempre me coloco, procuro me colocar no lugar daquele paciente. Como eu gostaria de ser manipulada se eu estivesse naquela situação? [...] Então, eu procuro manipular com meu toque. Na hora da higienização, de lidar com essas eliminações, esses excrementos e tal de uma forma mais natural possível [...]. A gente registra os odores, a gente registra, não tem como não registrar. Mas eu procuro ser 0 mais natural possível. E isso eu já observei que faz diferença. (Técnica de enfermagem).

Este tipo de exercício do cuidado é de difícil avaliação para os métodos que consideram apenas as mensurações. Sendo de difícil avaliação, é também de difícil reconhecimento, a não ser em espaços informais entre pares ou entre usuários e trabalhadores. No entanto, é justamente uma dinâmica intersubjetiva, a dinâmica do reconhecimento, que é capaz de proporcionar a passagem do sofrimento ao prazer no trabalho (DEJOURS, 2008B, 2012A, 2012B).

A teoria da psicodinâmica do trabalho parte do princípio que o sujeito, em sua relação com o trabalhar, espera contribuir para a organização do trabalho, tal como a técnica de enfermagem acima procura contribuir e não ser uma mera executora. A isso, Dejours chama de 'direito à contribuição'. A esta contribuição dada pelo trabalhador à organização real do trabalho é esperada uma retribuição que é fundamentalmente de natureza simbólica (DEJOURS, 2008D): o reconhecimento.

Essa retribuição simbólica confere sentido à experiência e à contribuição do trabalhador. A mesma técnica de enfermagem acima citada complementa: "Quando a gente faz de uma forma mais natural, o paciente percebe". Este efeito no paciente lhe propicia alguma gratificação, uma retribuição pelo esforço empreendido na tarefa. Esforço não apenas de executá-la, mas de realizá-la de modo 
sensível em relação às necessidades do paciente, de realizar a tarefa a seu modo, empregando seus saberes, sua 'inteligência prática'.

É dessa dinâmica intersubjetiva, fina e quase impalpável, de contribuir para a organização do trabalho e sentir o efeito dessa contribuição, por meio da percepção de um paciente, de um colega ou de um superior, que depende a mobilização subjetiva para o trabalho. Segundo Dejours (2008C), essa mobilização está sempre presente em todos os trabalhadores, desde que não seja desmobilizada por uma organização do trabalho que frustre o 'direito de contribuição'. A falta de reconhecimento da contribuição singular dos trabalhadores para a organização do trabalho se configuraria como obstáculo à emergência da mobilização subjetiva e, portanto, ao vínculo com o trabalho.

\section{Invisibilidade do trabalho e exigências da gestão}

Considerando que boa parte dos trabalhos em saúde são de cuidado e que estes, por sua vez, possuem características que os tornam pouco visíveis, se não totalmente invisíveis para os métodos de gestão e, consequentemente, não passíveis de apreensão direta ou mensuração, está-se diante do problema da relação dos trabalhadores de saúde com suas organizações e os muitos métodos de gestão que vêm sendo implantados na atualidade, em uma perspectiva que Gaulejac veio a chamar de "quantofrenia aguda" (GAULEJAC, 2007, P. 67).

Embora Gaulejac não se refira especificamente ao setor saúde e, ainda que reconhecendo que o setor público possui particularidades, se comparado às tendências gerenciais dominantes no setor privado, pode-se fazer uma reflexão acerca de tais questões no trabalho em saúde hoje no SUS, no Brasil. O contexto de implantação de novos modelos gerenciais nos serviços públicos de saúde, sem enfrentamento da situação de insuficiência de recursos humanos e, por vezes, acompanhado de enxugamento dos quadros de pessoal, pode impor limites importantes para a qualidade do cuidado e para as próprias gerências intermediárias, no que tange ao exercício de uso de mecanismos necessários para dar condições dignas aos sujeitos que trabalham.

O exercício do cuidado descrito acima pela técnica de enfermagem é mais do que a execução de uma higiene íntima: ela contribui para a organização do trabalho e percebe o sentimento do paciente, retornando-lhe como algo que lhe gratifica e que opera a passagem da execução para a contribuição, construindo e reconstruindo o vínculo com o trabalho e o trabalhar. $\mathrm{O}$ ato de executar um procedimento passa a ser, para aquela técnica, no exemplo da 'execução da higiene íntima', uma atividade em que é possível acrescentar de si ao trabalho prescrito, transformar um ato que, apesar de inicialmente penoso (limpar os excrementos de um paciente), passa a lhe dar algum prazer, pelas sutilezas da resposta do paciente ao seu cuidado.

No entanto, nem sempre é possível aos operadores do cuidado dispor desse tempo. A demanda incessante por produtividade atravessa as mais altas esferas das hierarquias no campo da saúde pública e desce em cascata, demandando de diretores, gerentes e, como consequência, trabalhadores do cuidado, números, indicadores, metas que nem sempre têm contrapartida no número de trabalhadores e nas condições de trabalho. Não se faz gestão sem metas e indicadores, é verdade. Estes elementos são fundamentais. No campo da saúde pública, eles são necessários para garantir acesso, equidade e formulação de políticas. Todavia, a questão que se coloca é que, cada vez mais, eles vêm tomando o lugar da interação humana e das informações qualitativas sobre os processos de trabalho, que também devem ter seu lugar nos processos de gestão, assim como espaços de visibilidade justamente para uma dimensão do trabalho que fica à sombra: sua dimensão invisível e não mensurável. 
Na pesquisa citada (FONSECA, 2014), foi detectado um certo grau de desmobilização para o trabalho a partir do relacionamento dos trabalhadores com a gestão. A mobilização, nesse caso, provinha tão somente da relação desses trabalhadores com os pacientes.

A desmobilização, expressa em falas, como "Não falo mais nada"; "Não me manifesto mais", "Não dou mais opinião", era oriunda principalmente de um sentimento de invisibilidade do esforço empreendido na tarefa de prover o cuidado para pacientes em condições não favoráveis ao exercício do cuidado no tempo que consideram adequado. Disse um técnico de enfermagem: " $E$ muito paciente com câncer para pouco leito e muito leito pra pouco profissional".

Uma enfermeira afirmou que "quase errou uma quimioterapia" e acrescentou: "Quem diz que consegue assobiar e chupar cana está mentindo".

$\mathrm{Na}$ mesma direção, outra enfermeira afirmou: "Eu não sou um polvo. Não posso. Eu falo. Eu não posso fazer três, como... Vai ficar uma porcariada tudo", apontando para a contradição entre qualidade do trabalho e metas e indicadores incompatíveis com a quantidade de trabalhadores disponíveis.

Entre esses trabalhadores, havia um ressentimento pela desvalorização, por parte da gestão, da dimensão humana, paralelamente à idealização da tecnologia e da técnica que atravessa as organizações de saúde, principalmente as de alta complexidade: "O ser humano tem que usar a tecnologia, entendeu? Eles esqueceram que para utilizar a tecnologia precisa do humano." (Técnica na entrevista coletiva).

Essa mesma dimensão humana que, no trabalho em oncologia, demandava desses trabalhadores a lida cotidiana com a vida e a morte em suas faces mais intensas também provocava a chamada "contaminação do tempo fora do trabalho" (SANTOS, 2001, P. 155), isto é, o levar para a casa a preocupação com os pacientes e com as questões da enfermaria.

Expressões, tais como, "da porta para fora" (do hospital) e "da porta para dentro", procurando produzir no discurso uma separação fictícia entre essas duas esferas, eram frequentes durante as entrevistas e observações realizadas na pesquisa aqui citada (FONSECA, 2014). Assim, enquanto "deixar as coisas do lado de fora" significava para eles tentar ser profissional e não trazer as questões de casa para o trabalho; "não levar coisas pra casa" significava tentar resistir em levar as tristezas do trabalho para o âmbito doméstico. Enquanto para alguns trabalhadores essa influência recíproca era evidente, outros passaram a se interrogar a respeito dessa separação, à medida que iam refletindo mais profundamente. Ao longo de uma entrevista individual, um técnico falou: "Eu não levo problemas para casa, eu acho que eu não levo... quer dizer agora já fiquei na dúvida até". Para outros trabalhadores, essa influência era evidente. Uma enfermeira confessou que quase bateu o carro ao sair de um plantão, tomada pelos eventos vividos na enfermaria. Uma técnica de enfermagem falou a respeito do falecimento de uma jovem:

\begin{abstract}
A Joana [nome fictício], quando morreu, ela estava com meu crachá na mão, segurando minha mão. Eu estou falando sério! Ela morreu, ela me chamava... 17 anos!!! Ela queria que eu ficasse do lado dela o tempo todo. E ela pra mim: 'Fica!'. Eu, na minha cabeça: 'Será que eu vou junto, depois dela? Ela está me chamando para eu ir com ela'. Que na cabeça da gente é umas coisas assim. Às vezes morre te chamando. Ela me chamava o tempo todo. Ela ficava: 'Maria, Maria' [nome fictício] e me chamando.
\end{abstract}

A técnica foi para casa escutando a voz da jovem. Dejours (2012A) adverte que o trabalho não se esgota no espaço geográfico onde se dá o trabalhar, mas coloniza a subjetividade. Nos trabalhos em saúde e, de forma mais intensa, no trabalho em oncologia, há uma intensidade de vivências que penetram a vida dos sujeitos, homens e mulheres, que trabalham de forma mais punjente. Não foram poucos os relatos a respeito dessa 'contaminação do 
tempo fora do trabalho'. Apesar disso, tais trabalhadores, que possuem vínculo de 40 horas semanais, são convocados a dispender $100 \%$ dessa carga horária na atenção direta ao paciente, lidando com essa intesidade de experiências em tempo integral.

\section{Os desafios de gerir (sustentar) um trabalho de insustentável leveza}

Pelo exposto até aqui, pode-se afirmar que a produção do cuidado em saúde se constitui essencialmente não apenas como um trabalho intangível, com muitas dimensões invisíveis, mas também, igualmente, como um trabalho que exige dos trabalhadores, daqueles que cuidam, um elevado esforço psíquico (no caso da enfermagem, na maioria das vezes, também grande esforço físico) para sustentar a necessária sensibilidade e leveza, na interação com os sujeitos e suas demandas de cuidado, em situações em geral atravessadas por muito sofrimento. Assim, trata-se de um trabalho que, embora exigindo leveza, é muitas vezes quase que insustentável. Por isso a alusão que fizemos no título deste artigo ao romance de Milan Kundera.

No entanto, diferentemente dos protagonistas do romance, para os quais a leveza na relação com o outro se traduzia pela fragilidade dos vínculos, pela dificuldade de responsabilização, o trabalho em saúde, aqui particularmente abordado através do trabalho da enfermagem, é exercido pela maioria dos profissionais como um trabalho de extrema intensidade de vínculos com os pacientes. Desse modo, para que possa ser bem exercido, precisa igualmente ser sustentado, e aqui destaca-se a importância da gestão em sua função de sustentação material e psíquica do trabalho em saúde.

O paradoxo apontado por um dos técnicos de enfermagem, quando afirma haver alta demanda de atendimento para poucos leitos e muitos leitos para poucos profissionais, configura-se como um drama cotidiano no gerenciamento do trabalho em oncologia no SUS. No âmbito da assitência oncológica, aliada à intensa mobilização psíquica que em geral caracteriza a maioria das situações deste tipo de cuidado, a demanda vem crescendo exponencialmente, em oposição a uma insuficiência de recursos humanos disponíveis. Por outro lado, ao invés de processos e dispositivos de gestão que promovam suporte aos trabalhadores para o enfrentamento de tais desafios, predominam pressões por metas cada vez mais altas, indicadores e 'excelência'. Excelência não necessáriamente pautada nas condições reais de produção do cuidado, mas na naquilo que Soboll e Horst (2013) chamaram de 'ideologia da excelência'.

Baseados em Christophe Dejours, esses autores afirmam que a ideologia de 'excelência', sistema de pensamento hegemônico no contexto atual de trabalho, que prima pelo 'mito da autossuperação e por resultados sempre superiores, subsidiando a crescente produtividade nas organizações', já pressupõe algo não partilhável, visto que, para ser 'excelente', é preciso que alguém esteja aquém:

O termo excelência, por sua vez, refere-se a algo que, de antemão, não é partilhável. Assumir uma conduta de excelência significa não partilhar esse objetivo com seus semelhantes. A excelência não é compartilhada. Para que um seja excelente é necessário outro que fique aquém. A busca da excelência tem como fundamento o individualismo e rompe com os laços de cooperação e de reconhecimento, essenciais para construção da identidade e da saúde do trabalhador. (SOBOL; HORST, 2013, P. 225).

Quando se trata de trabalho em saúde e, especialmente, de trabalhos de cuidado, a ideologia da excelência pode ser particularmente nefasta, na medida em que tende a não considerar (porque não consegue avaliar) suas dimensões invisíveis e não palpáveis. 
Centrada prioritariamente em metas e indicadores, imputa a responsabilidade sobre trabalhadores individualmente e não é capaz de reconhecer a importância da gestão não apenas para a garantia das condições materiais e tecnológicas para a realização do trabalho em saúde, mas também na promoção de espaços de sustentação subjetiva/intersubjetiva deste trabalho. Assim,

[...] para além dos necessários esforços de reorganização e melhoria das condições e dos processos de trabalho - e também, obviamente, de maior eficiência no uso dos recursos e efetividades das ações - é necessário, [...] buscar, propor e/ou fortalecer dispositivos e processos de gestão e organização do trabalho que favoreçam a gestores e trabalhadores de saúde o acesso a sua própria subjetividade - ao (re)conhecimento das fontes de seu sofrimento e prazer no trabalho, dos vínculos imaginários/afetivos que os ligam ao trabalho, às organizações, ao outro (profissional, usuário) e do sentido do trabalho em suas vidas. (SÁ, 2009, P. 658).

Trata-se, portanto, como já observado (SÁ, 2009) de buscar outros modos de se fazer gestão em saúde. Desenvolver capacidade de reconhecimento das dimensões intangíveis do trabalho em saúde e capacidade de escuta (e de resposta ou encaminhamento) do sofrimento (não só dos pacientes, mas também dos trabalhadores/gestores) e das demandas por sentido que atravessam a vida organizacional.

\section{Referências}

AYRES, J. R. O Cuidado, os modos de ser (do) humano e as práticas de saúde. Saúde e Sociedade, v. 13, n. 3, p. 16-29, set./dez. 2004.

BRITO, J. A. Ergologia como perspectiva de análise: a saúde do trabalhador e o trabalho em saúde. In: MINAYO-GOMES, C.; MACHADO, J. M. H.; PENA, P. G. L. (Org.). Saúde do trabalhador na sociedade brasileira contemporânea. Rio de Janeiro: Editora Fiocruz, 2011.

CAMPOS, G. W. S. A clínica do sujeito: por uma clínica reformulada e ampliada. In: Saúde Paidéia. São

Paulo: Hucitec, 2003.

DEJOURS, C. Trabalho vivo: sexualidade e trabalho. Brasília, DF: Editora Paralelo 15., 2012a.

Trabalho vivo: trabalho e emancipação. Brasília,

DF: Editora Paralelo 15., 2012b.

. Da psicopatologia à psicodinâmica do trabalho. In: LANCMAN, S.; SZNELZAR, L. I. (Org.). Chistophe Dejours: da psicopatologia à psicodinâmica do trabalho. Rio de Janeiro: Editora Fiocruz, Brasília, DF: Ed. Paralelo 15., 2008a.
. Entre sofrimento e reapropriação: o sentido do trabalho. In: LANCMAN, S.; SZNELZAR, L. I. (Org.). Chistophe Dejours: da psicopatologia à psicodinâmica do Trabalho. Rio de Janeiro: Ed. Fiocruz, Brasília, DF: Ed. Paralelo 15., 2008b.

Sofrimento e prazer no trabalho: A abordagem pela psicopatologia do trabalho. In: LANCMAN, S.; SZNELZAR, L. I. (Org.). Chistophe Dejours: da psicopatologia à psicodinâmica do Trabalho. Rio de Janeiro: Ed. Fiocruz, Brasília, DF: Ed. Paralelo 15., 2008c.

Inteligência prática e sabedoria prática: duas dimensões desconhecidas do Trabalho Real. In: LANCMAN, S.; SZNELZAR, L. I. (Org.). Chistophe Dejours: da psicopatologia à psicodinâmica do trabalho. Rio de Janeiro: Ed. Fiocruz, Brasília, DF: Ed. Paralelo 15., 2008d.

Subjetividade, trabalho e ação. Revista Produção, Santa Catarina, v. 14, n. 3, p. 27-34, set./dez. 2004.

Por um trabalho, fator de equilíbrio. Revista de Administração de Empresas, São Paulo, v. 33, n. 3, maio/jun., 1993. 
Por um novo conceito de saúde. Revista Brasileira de Saúde Ocupacional, São Paulo, v. 54, n. 14 maio/jun. 1982.

FONSECA, M. L. G. Da prescrição à criação: inteligência prática, produção de cuidado e invisibilidade no trabalho de uma equipe de enfermagem em oncologia. 2014. 251 f. Tese (Doutorado em Saúde Pública) Fundação Oswaldo Cruz, Rio de Janeiro, 2014.

GAULEJAC, V. A gestão como doença social: Ideologia, poder gerencialista e fragmentação social. Rio de Janeiro: Editora Idéias e Letras, 2007.

MARSIGLIA, R. M. G. Prefácio. In: BRITO, J; ASSUNÇÃO, A. A. (Org.). Trabalhar na saúde: experiências cotidianas e desafios para a gestão do trabalho e do emprego. Rio de Janeiro: Editora Fiocruz, 2011.

MERHY, E. E. Saúde a cartografia do trabalho vivo. São Paulo: Hucitec, 2002

MOLINIER, P. Ética e trabalho do Care. In: HIRATA, H.; GUIMARÃES, N. A. (Org.). Cuidado e cuidadoras: as várias faces do trabalho do Care. São Paulo: Editora Atlas, 2012.

SÁ, M. C. Em busca de uma porta de saída: os destinos da solidariedade, da cooperação e do cuidado com a vida na porta de entrada de um hospital de emergência. 2005. 453f. Tese (Doutorado em Psicologia) - São Paulo, Universidade de São Paulo, 2005.

A fraternidade em questão: um olhar psicossociológico sobre o cuidado e a humanização das práticas de saúde. Interface - Comunicação, Saúde, Educação, v. 13, n. 1, p. 651-664, 2009.

SANTOS, M. L. Cuidados paliativos e organização do trabalho: a concepção na atividade de técnicas e auxiliares de enfermagem. 2001. $221 \mathrm{f}$. Tese (Doutorado em Engenharia de Produção) - Universidade Federal do Rio de Janeiro, Rio de Janeiro, Fevereiro, 2001.

SCHAIBER, L. B. O médico e seu trabalho: limites da liberdade. Editora Hucitec, São Paulo, 1993.

SOBOLL, L. A. P.; HORST, A. C. Ideologia da Excelência. In: VIEIRA, F. O.; MENDES, A. M.; MERLO, A. R. C. Dicionário crítico de gestão e psicodinâmica do trabalho. Curitiba: Editora Juruá, 2013.

Recebido para publicação em abril de 2015

Versão final em setembro de 2015

Conflito de interesses: inexistente

Suporte financeiro: não houve 